\title{
INVENTARISASI JENIS-JENIS TUMBUHAN FAMILI EUPHORBIACEAE DI KECAMATAN TOPOS KABUPATEN LEBONG PROVINSI BENGKULU
}

\author{
Nopa Nopiyanti ${ }^{*}$, Linna Fitriani ${ }^{2}$ \\ ${ }^{12}$ STKIP PGRI Lubuklinggau, Jl. Mayor Toha Kel. Air Kuti, Lubuklinggau 31626, Indonesia \\ *Corresponding author, e-mail: nopachandra@yahoo.com
}

\section{ABSTRACT}

This study aims to determine the types of plants of the Euphorbiaceae family in Topos District, Lebong Regency, Bengkulu. The research was conducted in May-June 2018 in 7 villages in Topos District, Lebong Regency, Talang Baru 1 Village, Talang Baru 2 Village, Talang Donok 1 Village, Talang Donok 2 Village, Anjay Siang Village, Suka Negri Village, and Villages Bandar Agung. The study was conducted by survey and interview the specimens were taken and analyzed descriptively. From the results of the study founded 20 plant spesies Euphorbiaceae family with 11 genera, namely: Acalypha 1 spesies (Acalypha indica), Aleurites 1 spesies (Aleurites maluccana), Codiaeum 5 spesies (Codiaeum Sp, Codiaeum 'Finger', Codiaeum 'Cronstandt', Codiaeum variegatum 'Norma', Codiaeum variegatum 'Exsotica red'), Euphorbia 4 spesies (Euphorbia hirta, Euphorbia pulcherrima, Euphorbia milli, Euphorbia milli 'Golden eagle'), Excoecaria 1 spesies (Excoecaria chinchinensis), Hevea 1 spesies (Hevea brasilensis), Jartopha 2 spesies (Jatropha curcas, Jatropha gossypiifolia), Manihot 1 spesies (Manihot esculenta), Pedilanthus 1 spesies (Pedilanthus tithymaloides), Phyllanthus 2 spesies (Phyllanthus urinaria, Phyllanthus acidus), Sauropus 1 spesies (Sauropus androguns).

Keywords: Euphorbiaceae, Lebong, Topos, Plants

\section{PENDAHULUAN}

Indonesia merupakan negara kepulauan terbesar di dunia. Luas tanah darat lebih kurang dua ratus juta hektar dengan luas dan penyebaran wilayah seluas 162,335 juta hektar atau $81 \%$ tersebar di Sumatra, Sulawesi, dan Irian Jaya, masing-masing seluas 47.270 juta hektar, 53.966 juta hektar, 18.904 juta hektar, dan 42,195 juta hektar. Luas daratan tersebut terdiri 124.044 juta hektar berwujud tanah kering dan 38.291 juta hektar berwujud tanah basah yang tergolong kedalam tanah sawah, pasang surut, rawa bukan pasang surut, tanah bergambut (Munir,1996).

Kecamatan Topos Kabupaten Lebong Provinsi Bengkulu memiliki 7 desa dan 1 kelurahan dengan luas area $82,29 \mathrm{~km}^{2}$, sebagian besar wilayah tersebut masih banyak ditemukan hutan primer dan memiliki iklim yang sangat baik bagi habitat flora dan fauna. Berdasarkan hasil survey yang telah dilakukan di Kecamatan Topos banyak ditemukan tumbuhan jenis family Euphorbiaceae, selain dibudidayakan jenis tanaman tersebut banyak yang tumbuh secara liar. Namun demikian belum ada data valid mengenai jenis tumbuhan family Euphorbiaceae di Kabupaten Lebong.

Beberapa jenis tumbuhan family Euphorbiaceae mempunyai manfaat bagi kesehatan, diantaranya: Ekor kucing (Acalypha hispida) yang berkhasiat untuk menghentikan pendarahan dan peluruh kencing (Dalimartha, 2000) dan jarak pagar (Jatropha curcas) berkhasiat sebagai tanaman obat, selain itu minyak nabati dari tanaman ini dapat diolah menjadi bahan bakar pengganti minyak bumi dan pengganti energi fosil (Prihanda \& Hendroko, 2006). 
Dilihat dari permasalahan di atas oleh karena itu diperlukan penelitian tentang Inventarisasi Jenis-Jenis Tumbuhan Family Euphorbiaceae yang terdapat di Kecamatan Topos Kabupaten Lebong Provinsi Bengkulu.

\section{ME T ODE}

Penelitian ini dilakukan pada bulan Mei-Juni 2018, bertempat di Kecamatan Topos Kabupaten Lebong Provinsi Bengkulu dan di Laboratorium STKIP PGRI Lubuklinggau. Alat yang digunakan dalam penelitian ini adalah: baskom, kardus, kantong plastik, triplek, koran, parang, kertas label, thermometer, altimeter, buku lapangan, alat tulis, dan kamera. Bahan yang digunakan adalah alkohol 70\%.

Pengambilan tanaman Euphorbiaceae di Kecamatan Topos dilakukan menggunakan metode survey dengan cara menjelajah lokasi penelitian yang terdiri dari 7 Desa. Sampel yang ditemukan di lapangan, dicatat data dari tumbuhan tersebut yang meliputi habitat dan faktor abiotiknya. Setiap sampel yang ditemukan difoto dan dibuat herbarium. Kemudian dilakukan pengukuran tentang data-data abiotik seperti suhu udara dan ketinggian tempat. Sampel yang diperoleh selanjutnya diidentifikasi di laboratorium STKIP PGRI Lubuklinggau. Kegiatan identifkasi berpedoman pada buku panduan yaitu: Tjitrosoepomo (1996), Dalimartha (2002), dan Van Stenis (1997). Data yang terkumpul diklasifikasikan menurut jenis, sifat atau kondisinya (Arikunto, 2010). Penelitian ini bersifat kualitatif karena data yang telah terkumpul melalui prosedur penelitian yang menghasilkan data deskriptif berupa kata-kata tertulis atau lisan dari orang-orang dan perilaku yang dapat diamati (Margono, 2007).

\section{HASIL DAN PEMBAHASAN}

Jenis-jenis tumbuhan Euphorbiaceae yang ditemukan di Kecamatan Topos Kabupaten Lebong selama penelitian sebanyak 20 jenis dari 11 genus (Tabel 1).

Tabel 1.Jenis-jenis Tumbuhan Family Euphorbiaceae yang di Kecamatan Topos

\begin{tabular}{|c|c|c|c|c|}
\hline No & Genus & Spesies & Nama Indonesia & Nama Lokal \\
\hline 1 & Acalypha & Acalypha indica & Kucing-kucingan & $\begin{array}{l}\text { Daun kucing- } \\
\text { kucingan }\end{array}$ \\
\hline \multirow[t]{3}{*}{2} & Aleurites & Aleurites maluccana & Kemiri & Mingoi \\
\hline & & Codiaeumsp & Puring & Puring \\
\hline & & Codiaeum Finger & Puring jari & Puring \\
\hline \multirow[t]{3}{*}{3} & Codiaeum & CodiaeumCronstandt & Puring Cronstandt & Puring \\
\hline & & $\begin{array}{c}\text { Codiaeum variegatum } \\
\text { 'Norma }\end{array}$ & Puring ‘Norma & Puring \\
\hline & & $\begin{array}{l}\text { Codiaeum variegatum } \\
\text { 'Exsotica red' }\end{array}$ & $\begin{array}{l}\text { puring 'Exsotica } \\
\text { red' }\end{array}$ & Puring \\
\hline \multirow[t]{4}{*}{4} & Euphorbia & Euphorbia hirta & Patikan kerbau & Patikan kebo \\
\hline & & Euphorbia pulcherrima & Kastuba & Kastuba \\
\hline & & Euphorbia milli & Euphorbia & Bungo scorbia \\
\hline & & $\begin{array}{l}\text { Euphorbia milli 'Golden } \\
\text { eagle' }\end{array}$ & $\begin{array}{c}\text { Euphorbia 'Golden } \\
\text { eagle' }\end{array}$ & $\begin{array}{l}\text { Bungo scorbia } \\
\text { putih }\end{array}$ \\
\hline 5 & Excoecaria & Excoecaria chinchinensis & Sambang darah & Sambang darah \\
\hline 6 & Hevea & Hevea brasilensis & Karet & Kait \\
\hline \multirow[t]{2}{*}{7} & Jatropha & Jatropha curcas & Jarak pagar & Jarak \\
\hline & & Jatropha gossypiifola & Jarak kosta merah & Jarak \\
\hline 8 & Manihot & Manihot esculenta & Ubi kayu & Ubai kiu \\
\hline 9 & Pedilanthus & Pedilanthus tithymaloides & Tumbuhan zig zag & Daun keris \\
\hline \multirow[t]{2}{*}{10} & Phyallanthus & Phyallanthus urinaria & Meniran & Daun semanik \\
\hline & & Phyallanthus acidus & Ceremai & Cermei \\
\hline 11 & Sauropus & Sauropus andrigiuns & Katuk & Katu \\
\hline
\end{tabular}


Berdasarkan hasil penelitian di Kecamatan Topos Kabupaten Lebong, diperoleh 20 jenis tumbuhan family Euphorbiaceae dengan 11 genus yaitu : Genus Acalypha diperoleh 1 spesies, yaitu Acalypha indica, genus Aleurites diperoleh 1 spesies yaitu : Aleurites maluccana, genus Codiaeum diperoleh 5 spesies yaitu : Codiaeumsp, Codiaeum 'Finger', Codiaeum 'Cronstandt', Codiaeum variegatum 'Norma', dan Codiaeum variegatum 'Exsotica red', genus Euphorbiadiperoleh 4 spesies yaitu : Euphorbia hirta, Euphorbia pulcherrima, Euphorbia milli, dan Euphorbia milli 'Golden eagle', genus Excoecaria diperoleh 1 spesies yaitu : Excoecaria chinchinensis, genus Hevea diperoleh 1 spesies yaitu : Hevea brasilensis, genus Jatrophadiperoleh 2 spesies yaitu : Jatropha curcas dan Jatropha gossypiifolia, genus Manihot diperoleh 1 spesies yaitu : Manihot esculenta, genus Pedilanthus diperoleh 1 spesies yaitu : Pedilanthus tithymaloides, genus Phyllanthus diperoleh 2 spesies yaitu : Phyllanthus urinaria dan Phyllanthus acidus, dan yang terakhir genus Sauropus diperoleh 1 spesies yaitu : Sauropus androgiuns. Perbandingan jenis tumbuhan famili Euphorbiacea yang ditemukan pada setiap Desa yang diteliti dapat dilihat pada Tabel.2

Genus Acalypha, species yang ditemukan adalah Acalypha indica. Species ni banyak ditemukan di pinggir jalan, lapangan rumput, maupun lereng bukit. Menurut Dalimartha (2000), kucing-kucingan (Acalypha indica) merupakan gulma dengan ciri-ciri yakni batang bercabang dengan garis memanjang kasar, daun bertangkai panjang, letak tersebar. Helaian daun berbentuk bulat telur sampai lanset, tipis, ujung dan pangkal runcing, tepi bergerigi, berwarna hijau. Bunga majemuk, berkelamin satu, keluar dari ketiak daun, kecil-kecil dalam rangkaian berbentuk bulir. Akarnya tunggang. Akar tumbuhan ini sangat disukai oleh Kucing dan Anjing, yang dikonsumsi dengan cara dikunyah. Kucing-kucingan ini dapat diperbanyak dengan biji. Acalypha indica dapat dimanfaatkan sebagai obat, karena daun, batang, dan akar mengandung saponin dan tanin. Batangnya juga mengandung flavonoid dan daunnya menagndung minyak asitri. Tanaman Acalypha sudah terbukti memiliki kegunaan yang luas di berbagai negara dan dilaporkan memiliki sifat diuretik, pencahar, antihelmintik, selain juga digunakan untuk penyakit bronkitis, asma, pneumonia, kudis, dan kutaneous lainnya (Rajaselvam,dkk.2012).

Genus Aleurites merupakan genus yang sudah dibudidayakan dan di kembangkan oleh masyarakat setempat karena selain sebagai bumbu dapur, species ini juga bermanfaat sebagai obat yaitu minyak kemiri dapat digunakan sebagai penyubur rambut, bijinya dapat digunakan untuk tumor. Genus Codiaeum merupakan genus yang banyak ditemukan di pinggir-pinggir jalan dan tumbuh liar. Genus ini kaya akan manfaat. Air rebusan puring berwarna hijau tua bisa digunakan untuk memperlancar keluarnya keringat jika dipakai mandi. Bubur hasil tumbukan akar dan batang puring dapat dimanfaatkan sebagai obat pencegah penyakit kelamin raja singa (Lestari, 2008). Pengolahan tumbuhan dengan cara direbus didukung oleh penelitian Mabel dkk (2016) tentang identifikasi Dan Pemanfaatan Tumbuhan Obat Suku Dani Di Kabupaten Jayawijaya Papua, menurut hasil penelitian tersebut pengolahan dengan cara direbus juga paling banyak digunakan masyarakat Kabupaten Jayawijaya Papua. Merebus dianggap lebih mudah untuk mengeluarkan zat yang bermanfaat di dalam tumbuhan supaya larut dalam air. Air rebusan tersebut dapat di minum atau dimandikan sesuai pengolahan ramuan obat setiap jenis penyakit. Sehingga air rebusan tersebut lebih mudah diserap atau diproses oleh tubuh. 
Tabel 2. Daftar jenis-jenis tumbuhan family Euphorbiaceae yang Ditemukan Setiap Desa

\begin{tabular}{|c|c|c|c|c|c|c|c|c|}
\hline \multirow[t]{2}{*}{ No } & \multirow[t]{2}{*}{ Spesies } & \multicolumn{7}{|c|}{ Spesies yang ditemukan pada desa } \\
\hline & & $\begin{array}{l}\text { Talang } \\
\text { Baru } 1\end{array}$ & $\begin{array}{l}\text { Talang } \\
\text { Baru } 2\end{array}$ & $\begin{array}{c}\text { Talang } \\
\text { donok } \\
1\end{array}$ & $\begin{array}{c}\text { Talang } \\
\text { Donok } \\
2\end{array}$ & $\begin{array}{l}\text { Anjay } \\
\text { siang }\end{array}$ & $\begin{array}{l}\text { Suka } \\
\text { Negri }\end{array}$ & BandarAgung \\
\hline 1 & $\begin{array}{l}\text { Acalypha } \\
\text { indica }\end{array}$ & + & + & + & + & + & + & + \\
\hline 2 & $\begin{array}{l}\text { Aleurtes } \\
\text { maluccana }\end{array}$ & + & + & + & + & + & + & + \\
\hline 3 & Codiaeum sp & + & + & + & + & - & - & - \\
\hline 4 & $\begin{array}{l}\text { Codiaeum } \\
\text { figer }\end{array}$ & - & - & + & + & - & - & - \\
\hline 5 & $\begin{array}{l}\text { Codiaeumc } \\
\text { ronstandt }\end{array}$ & + & + & + & + & - & - & - \\
\hline 6 & $\begin{array}{l}\text { Codiaeum } \\
\text { variegatum } \\
\text { 'Norma' }\end{array}$ & + & + & + & + & - & - & - \\
\hline 7 & $\begin{array}{l}\text { Codiaeum } \\
\text { variegatum } \\
\text { 'Exsotica } \\
\text { red' }\end{array}$ & - & - & - & - & - & + & + \\
\hline 8 & $\begin{array}{l}\text { Euphorbia } \\
\text { hirta }\end{array}$ & + & + & + & + & + & + & + \\
\hline 9 & $\begin{array}{l}\text { Euphorbia } \\
\text { pulcherrima }\end{array}$ & + & + & + & + & + & + & + \\
\hline 10 & $\begin{array}{l}\text { Euphorbia } \\
\text { milli }\end{array}$ & + & + & + & + & + & + & + \\
\hline 11 & $\begin{array}{l}\text { Euphorbia } \\
\text { milli 'Golden } \\
\text { eagle' }\end{array}$ & + & + & + & + & + & + & + \\
\hline 12 & $\begin{array}{l}\text { Excoecaria } \\
\text { chinchinensi } \\
S\end{array}$ & + & + & - & - & - & + & + \\
\hline 13 & $\begin{array}{l}\text { Hevea } \\
\text { brasilensis }\end{array}$ & + & + & + & + & + & + & + \\
\hline 14 & $\begin{array}{l}\text { Jatropha } \\
\text { curcas }\end{array}$ & + & + & + & + & + & + & + \\
\hline 15 & $\begin{array}{l}\text { Jatropha } \\
\text { gossypiifolia }\end{array}$ & + & + & - & - & - & + & - \\
\hline 16 & $\begin{array}{l}\text { Manihot } \\
\text { esculenta }\end{array}$ & + & + & + & + & + & + & + \\
\hline 17 & $\begin{array}{l}\text { Pedilanthus } \\
\text { tithymaloide } \\
S\end{array}$ & + & + & + & + & + & + & + \\
\hline 18 & $\begin{array}{l}\text { Phyllanthus } \\
\text { urinaria }\end{array}$ & + & + & + & + & + & + & + \\
\hline 19 & $\begin{array}{l}\text { Pyllanthus } \\
\text { acidus }\end{array}$ & - & - & - & - & + & - & - \\
\hline 20 & $\begin{array}{l}\text { Sauropus } \\
\text { androgiuns }\end{array}$ & + & + & + & + & + & + & + \\
\hline
\end{tabular}

Ket: - = Tidak ditemukan

$+=$ Ditemukan

Genus Euphorbia, genus ini ditemukan 4 species yakni Euphorbia hirta, Euphorbia pulcherrima, Euphorbia milli, dan Euphorbia milli 'golden eagle'. Menurut Haryanto (2009), Euphorbia hirta merupakan tumbuhan liar yang banyak ditemukan di daerak kawasan tropis. Species ini dapat ditemukan di pinggir jalan, sungai, kebunkebun, atau tanah pekarangan rumah yang sudah terlantar. Euphorbia hirta atau yang 
sering di sebut patikan kerbau ini dapat dimanfaatkan sebagai tanaman obat. Euphorbia pulcherrima atau sering disebut Kastuba, biasa diemukan pada 1-1400 m dpl. Rasanya pahit, sepat, sifatnya sejuk. Berkahasiat sebagai perangsang muntah, menormalkan silkus haid, menghentikan pendarahan (hemostatis), mempercepat penyembuhan tulang yang patah, menghilangkan bengkak, dan melancarkan ASI (Haryanto, 2009). Bagian tumbuhan banyak dimanfaatkan sebagai obat adalah daun. Hal ini disebabkan bagian daun merupakan bagian yang sangat mudah dijumpai dan selalu tersedia, pengambilan dan pemanfaatannya tergolong mudah dan sederhana. Selain itu karena khasiat daun diketahui secara turun temurun lebih banyak dalam segi penyembuhannya dibandingkan dengan bagian yang lain. Menurut Patimah (2010) pada daun diduga banyak terakumulasi senyawa metabolit sekunder yang berguna sebagai obat, seperti tannin, alkaloid, minyak atsiri dan senyawa organik lainnya yang tersimpan di vakuola ataupun pada jaringan tambahan pada daun seperti trikoma. Dua (2) species ini yakni Euphorbia milli dan Euphorbia milli 'Golden eagle' merupakan tanaman yang mempunyai nilai ekonomis yang tinggi, karena warna bunganya bermacam-macam, selain itu dapat dimanfaatkan sebagai tanaman obat (Haryanto, 2009).

Tabel 3. Suhu dan Ketinggian Desa di Kecamatan Topos

\begin{tabular}{llcccc}
\hline No & Nama Desa & \multicolumn{3}{c}{ Suhu Udara } & $\begin{array}{c}\text { Ketinggian } \\
\text { (Dari permukaan air } \\
\text { laut) }\end{array}$ \\
\cline { 2 - 5 } & & Pagi & Siang & Sore & $120 \mathrm{~m}$ \\
\hline 1 & Talang Donok 1 & $23^{\circ} \mathrm{C}$ & $30^{\circ} \mathrm{C}$ & $25^{\circ} \mathrm{C}$ & $200 \mathrm{~m}$ \\
2 & Talang Donok 2 & $23^{\circ} \mathrm{C}$ & $31^{\circ} \mathrm{C}$ & $26^{\circ} \mathrm{C}$ & $170 \mathrm{~m}$ \\
3 & Talang Baru 1 & $24^{\circ} \mathrm{C}$ & $30^{\circ} \mathrm{C}$ & $26^{\circ} \mathrm{C}$ & $130 \mathrm{~m}$ \\
4 & Talang Baru 2 & $24^{\circ} \mathrm{C}$ & $30^{\circ} \mathrm{C}$ & $26^{\circ} \mathrm{C}$ & $160 \mathrm{~m}$ \\
5 & Suka Negri & $25^{\circ} \mathrm{C}$ & $31^{\circ} \mathrm{C}$ & $26^{\circ} \mathrm{C}$ & $170 \mathrm{~m}$ \\
6 & Anjay Siang & $24^{\circ} \mathrm{C}$ & $30^{\circ} \mathrm{C}$ & $26^{\circ} \mathrm{C}$ & $190 \mathrm{~m}$ \\
7 & Bandar Agung & $24^{\circ} \mathrm{C}$ & $31^{\circ} \mathrm{C}$ & $26^{\circ} \mathrm{C}$ & \\
\hline
\end{tabular}

Sumber : hasil pengamatan

Catatan : Pada penelitian ini tidak dipelajari kisaran suhu kritis yang tidak dapat ditoleransi oleh family Euphorbiaceae. Penelitian ini hanya mengungkapkan suhu normal yang dapat menunjang kehidupan family Euphorbiaceae di lokasi penelitian secara umum.

Genus Excoecaria, species yang ditemukan adalah Excoecaria chinchinensis. Species ini termasuk tanaman perdu yang cocok dijadikan sebagai tanaman hias. Getahnya bersifat toksik sehingga ada yang menyebutnya blindness tree atau pohon penyebab kebutaan (Dalimartha, 2008). Genus Hevea, species yang ditemukan adalah Hevea brasilensis. Hevea brasilensis merupakan pohon yang tingginya bisa mencapai $25 \mathrm{~m}$ dengan diameter yang cukup besar. Umumnya batang tumbuh lurus ke atas dengan percabangan di bagian atas. Di batang inilah terkandung getah yang lebih dikenal dengan nama 'Lateks'. Lateks inilah yang dapat dimanfaatkan, diantaranya ialah bermanfaat dalam pembuatan ban kendaraan, digunakan dalam industry, dan dalam perkembangannya, species ini juga merupakan bahan yang banyak dimanfaatkan untuk pembuatan bagian-bagian mesin perang (Heru dan Andoko, 2008).

Genus Jatropha, diperoleh 2 species yakni Jatropha curcas dan Jatropha gossypiifolia. Jatropha gossypiifolia sering disebut jarak kosta merah karena warna daunnya yang merah. Menurut Haryanto (2009), tanaman ini umumnya tumbuh liar di tepi jalan, lapangan rumput, atau di semak, pada tempat-tempat terbuka yang terkena sinar matahari di dataran rendah. Tanaman ini dapat dimanfaatkan sebagai 
tanaman obat, seperti radang anak telinga, pembengkakan dan penyakit kulit, demam, perangsang muntah.

Genus Manihot, diperoleh 1 species yakni Manihot esculenta. Di Indonesia, Manihot esculenta atau yang dikenal dengan nama ubi kayu dijadikan makanan pokok nomor tiga setelah padi dan jagung (Rukmana, 1997). Menurut Haryanto (2009), Hevea brasilensis dapat dimanfaatkan sebagai tanaman obat, tanaman ini dapat mengobati beberapa penyakit, diantaranya adalah Demam, Sakit kepala, diare, nafsu makan.

Genus Pedilanthus, diperoleh 1 species yakni Pedilanthus tithymaloides. Pertumbuhan batang tanaman ini cukup unik, yakni berselang-seling. Termasuk tanaman rumah yang mudah tumbuh. Batangnya silindris panjang dan bergetah. Hatihati terhadap getah tersebut karena bisa mennyebabkan rasa panas pada kulit (Dalimartha, 2008).

Genus Phyllanthus, diperoleh 2 species yakni Phyllanthus urinaria dan Phyllanthus acidus. Phyllanthus urinaria atau dalam bahasa Inonesianya Meniran, merupakan species yang mudah didapat. Menurut Haryanto (2009), species ini berbentuk bulat berbatang basah dengan tinggi kurang dari $50 \mathrm{~cm}$. species ini berasal dari daerah tropis yang tumbuh liar di hutan-hutan, ladang, kebun, maupun pekarangan halaman rumah, pada umumnya tidak dipelihara, karena dianggap tumbuhan rumput biasa. Meniran tumbuh subur di tempat yang lembab pada dataran rendah sampai ketinggian $1000 \mathrm{~m}$ di atas permukaan laut. Species ini dapat dimanfaatkan sebagai obat pada beberapa penyakit, diantaranya lever, malaria, demam, batuk, ayan, luka bakar.

Phyllanthus acidus atau dalam bahasa sehari-hari adalah ceremai, pohon ini berasal dari India, dapat tumbuh pada tanah ringan sampai berat dan tahan akan kekurangan atau kelebihan air. Orang-orang biasanya menanam ceremai di halaman, di ladang, dan tempat lain sampai ketinggian $1000 \mathrm{~m}$ dpl. Buah muda bisa dimasak bersama sayuran untuk menyedapkan masakan karena member rasa asam. Buah masak dapat dimakan langsung setelah diremas denagn air garam untuk mengurangi rasa sepat dan asam, dimakan setelah dibuat manisan atau selai. Selain itu ceremai dapat digunakan sebagai obat, yang dapat menyembuhkan beberapa penyakit, diantarnya ialah batuk berdahak, menguruskan badan, mual, sariawan ( Haryanto, 2009).

Genus Sauropus, diperoleh 1 species yakni Sauropus androgiuns. Spesies ini merupakan tanaman perdu, tinggi 2-5 m. batang berkayu, bulat, bekas daun tampak jelas, daun muda berwarna hijau dan setelah tua berwarna cokelat kehijauan. Species ini bermanfaat dalam memperlancar ASI ibu, selain itu dapat juga mengobati demam, suara parau (Haryanto, 2009).

Berdasarkan hasil yang di dapat pada tabel.3, terdapat 12 spesies yang paling banyak ditemukan di setiap desa yaitu Acalypha indica, Aleurites maluccana, Euphorbia hirta, Euphorbia pulcherrima, Euphorbia milli, Euphorbia milli 'Golden eagle', Hevea brasilensis, Jatropha curcas, Manihot esculenta, Pedilanthus titymaloides, Phyllanthus urinaria, dan Sauropus androgiuns. Hal ini disebabkan karena tumbuhtumbuhan ini (Acalypha indica, Aleurites maluccana, Euphorbia hirta, Euphorbia pulcherrima, Euphorbia milli, Euphorbia milli 'Golden eagle', Hevea brasilensis, Jatropha curcas, Pedilanthus titymaloides, Phyllanthus urinaria) merupakan tumbuhan liar dan dapat di jumpai dimana-mana terutama ditempat terbuka, seperti di pinggiran jalan, semak-semak, tanah terlantar dan di antara rerumputan. 2 species lainnya yaitu Hevea brasilensis dan Manihot esculenta merupakan tanaman yang 
banyak ditanam oleh masyarakat setempat, khususnya Hevea brasilensis yang dijadikan sebagai tanaman komoditi daerah setempat. Sedangkan species yang paling sedikit ditemukan adalah Pyllanthus acidus. Hal ini disebabkan masyarakat cenderung menanam atau memelihara tumbuhan yang memilki nilai tambah dalam hal ekonomi atau punya manfaat langsung terhadap pertanian mereka.

Penelitian Hermin, dkk (2016) tentang kajian Etnofarmasi Etnik Bungkudi kecamatan Bungku Tengah Kabupaten Morowali Provinsi Sulawesi Tengah juga menunjukkan hasil bahwa jenis famili euphorbiaceae merupakan famili yang paling banyak di Kabupaten Morowali. Hal tersebut dikarenakan banyak jenis penyakit yang menggunakan tumbuhan dari famili euphorbiaceae sebagai pengobatan bagi masyarakat setempat. Selain itu, penelitian Ilmana (2015) tentang pemanfaatan tumbuhan obat pada masyarakat Kota Ternate, Maluku Utara juga menunjukkan bahwa dari 74 spesies yang ditemukan tumbuhan yang paling banyak digunakan didominasi dari famili euphorbiaceae.

Penelitian Setyowati (2006) tentang pengetahuan masyarakat Talang Mamak tentang pemanfaatan tumbuhan obat Di Taman Nasional Bukit Tiga Puluh, Jambi juga menunjukkan hasil bahwa jenis famili euphorbiaceae merupakan famili yang paling banyak digunakan masyarakat setempat.

\section{S I M P ULA N}

Berdasarkan hasil penelitian diperoleh terdapat 12 spesies yang paling banyak ditemukan di setiap desa yaitu Acalypha indica, Aleurites maluccana, Euphorbia hirta, Euphorbia pulcherrima, Euphorbia milli, Euphorbia milli 'Golden eagle', Hevea brasilensis, Jatropha curcas, Manihot esculenta, Pedilanthus titymaloides, Phyllanthus urinaria, dan Sauropus androgiuns. Sedangkan spesies yang paling sedikit ditemukan adalah Pyllanthus acidus.

\section{REF EREN S I}

Arikunto, S. (2010). Prosedur Penelitian Suatu Pendekatan Praktek. Jakarta: PT Rineka Cipta.

Dalimartha, S. (2000). Atlas Tumbuhan Obat Indonesia. Jakarta: Trubus Agriwidya. Fauzi, A. (2009). Aneka Tanaman Obat dan Khasiatnya. Yogyakarta: Media Pressindo. Haryanto, S. (2009). Ensiklopedi Tanaman Obat Indonesia. Yogyakarta: Palmall. Heru, A. (2008). Petunjuk Lengkap Budi Daya Karet. Jakarta: Agromedia pustaka.

Hermin, Ibrahim N., \& Nugrahani, A.W. (2016). Kajian Etnofarmasi Etnik Bungkudi Kecamatan Bungku Tengah Kabupaten Morowali Provinsi Sulawesi Tengah. GALENIKA Journal Of Pharmacy, 2 (2): 76-82.

Ilmana, A. (2015). Pemanfaatan Tumbuhan Obat Pada Masyarakat Kota Ternate Maluku Utara. Bogor

Lestari, G. (2008). Si Daun Atraktif Puring. Jakarta: Prima infosarana media.

Mabel, Y., Simbala, H \& Koneri, R. (2016). Identifikasi Dan Pemanfaatan Tumbuhan Obat Suku Dani Di Kabupaten Jayawijaya Papua. Jurnal Mipa Unsrat Online, 5(2): 103-107.

Margono, S. (2007). Metodologi Penelitian Pendidikan. Jakarta: PT. Rineka Cipta

Munir, M. (1996). Tanah-Tanah Utama Indonesia. Jakarta: Pustaka Jaya.

Prihandana, R., \& Hendroko, R. 2006. Petunjuk Budidaya Jarak pagar. Jakarta: Agromedia Pustaka.

Ratnasari, J. (2007). Galeri Tanaman Hias Bunga. Jakarta: Penebar Swadaya. 
(2008). Galeri Tanaman Hias Daun. Jakarta: Penebar Swadaya.

Rajaselvam J, Benila smily J. M \& Meena R. (2012). A Study of Antimicrobial Activity of Acalypha indica against Selected Microbial Spesies. International Journal of Pharma Sciences and Research, 3(9):473-476

Rukmana. (1997). Ubi Kayu Budi Daya dan Pascapanen. Yogyakarta: Kanisius.

Setyowati, M.F. (2006). Pengetahuan Masyarakat Talang Mamak Tentang Pemanfaatan Tumbuhan Obat di Taman Nasional Bukit Tiga Puluh Jambi. Jurnal Bahan Alam Indonesia, 5 (1), 321-325

Steenis, Van.C.G.G.J. (1997). Flora. Jakarta: Pradnya Paramitha .

Tjitrosoepomo, G. (1996). Taksonomi Tumbuhan (Spermathopyta). Yogyakarta: Gajah Mada University Press.

(1997). Taksonomi Tumbuhan Obat-obatan. Yogyakarta.: Gajah Mada University Press. 